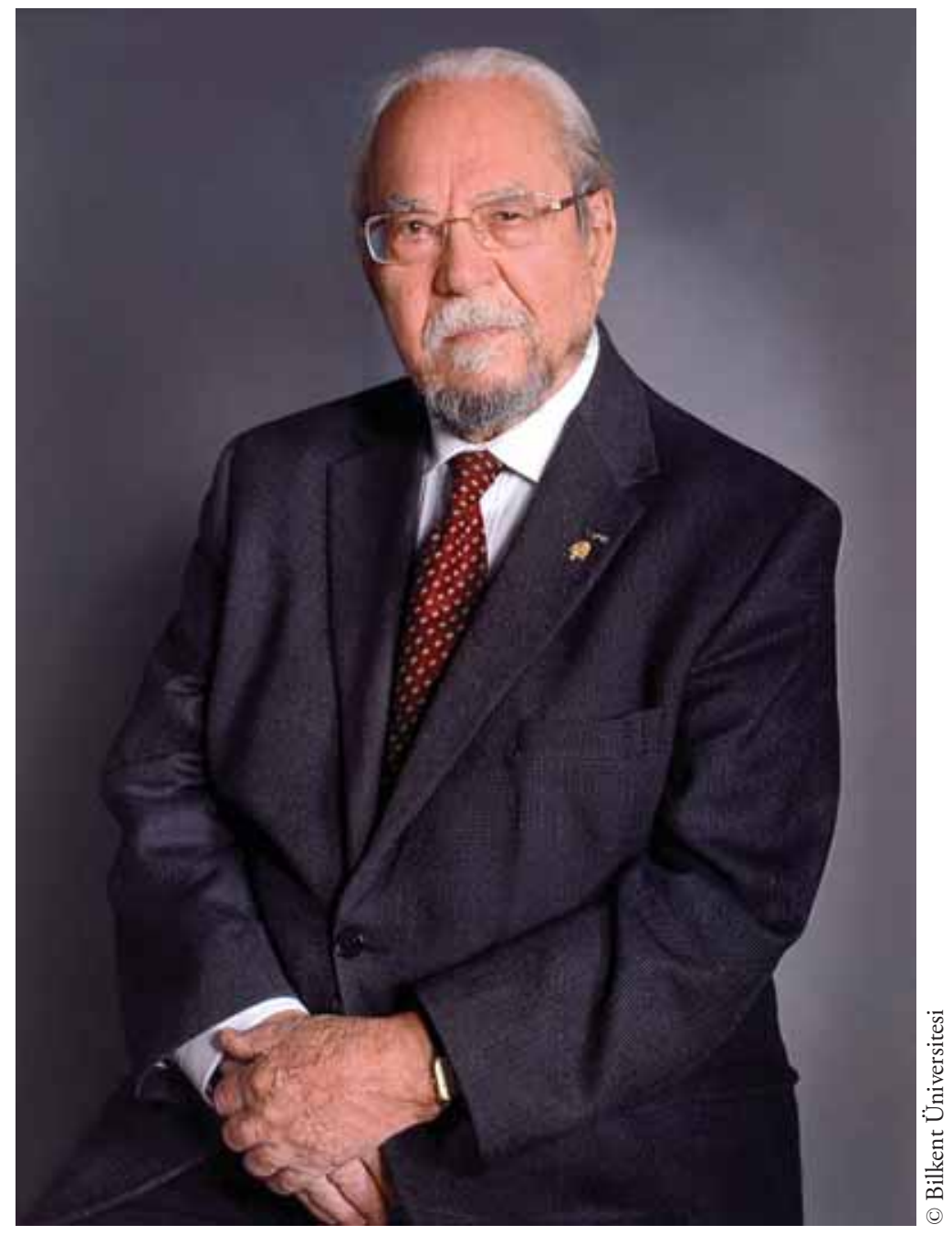

Prof. Dr. Halil İnalcık (1916-2016) 



\section{Hocaların Hocası Halil İnalcık’ın Ardından}

Seyfi Kenan*

Dergimizin kurucularından Prof. Dr. Halil İnalcık Hocamız, 25 Temmuz 2016'da vefat etti. Acımız ve kaybımız sonsuzdur. Sadece bir tarihçiyi değil, aynı zamanda çok kıymetli bir insanı ve bilim adamını; bir duruşun, ilim tarzının ve ifadesinin âbidesini de kaybettik. Bir âlimin vefatının, bir âlemin de ölümü gibi olduğunu bir kez daha derin teessürle anladık.

Haklı olarak "Hocaların Hocası" olarak anılan Halil İnalcık, 1916'da sıkıntılarla dolu Osmanlı İstanbul'unda dünyaya geldi. Temel eğitimine Cumhuriyet'in ilanına denk gelen yılda, 1923'te Ankara Gazi Mektebi'nde başladı ve orta tahsilini Ankara Gazi Muallim Mektebi'nde tamamladı. Lise eğitimini ise Balıkesir Necati Bey Muallim Mektebi'nde bitirdi. ilk gençlik yıllarını ortaokuldan lise sona kadar öğretmen okullarında geçirmesi, onda öncelikle güçlü bir eğitimci ve öğretmen zihniyetinin oluşumunu sağladığında şüphe yok. Daha sonra üniversite yıllarından başlayarak bir asırlık ömrünün son anlarına kadar devam edecek tarihçiliğinin şekillenmesinde ve etkinliğinde bu gençlik yıllarında aldığ1 temel eğitim etkili olmuştur.

1936'da Ankara Dil, Tarih ve Coğrafya Fakültesi, Yeni Çağ Tarihi bölümünde yüksek öğrenimine başladı. Mezun olduktan sonra 1940'da aynı fakültede asistan oldu. Tanzimat ve Bulgar Meselesi teziyle 1942'de doktorasinı tamamladı. 1952'de profesör oldu. Uzun yıllar aynı fakültede Osmanlı ve Avrupa tarihi üzerine dersler verdikten ve pek çok öğrenci yetiştirdikten sonra 1972'de emekli oldu. Chicago Üniversitesi Tarih bölümüne “Osmanlı Tarihi Üniversite

\footnotetext{
* Marmara Üniversitesi.
} 
Profesörü” olarak davet edilince Amerika'ya gitti ve 1973'de ünlü The Ottoman Empire: The Classical Age 1300-1600 adlı eseri yayınlandı. Yirmi yılı aşkın bir süre boyunca orada da dersler vermeye, eserler yazmaya, tezler yönetmeye ve de kendi ismini yüceltecek pek çok öğrenci yetiştirmeye devam etti.

Amerika'daki çalışmalarını sürdürürken Türkiye ile irtibatını kaybetmeyen Halil İnalcık, 1980'de İstanbul'da ilim dünyasına ayak basan ve Osmanlı Araştırmaları adını taşıyan dergimiz kurucuları arasında yer aldı. 1986'da Chicago Üniversitesi'nden emekli oldu ve 1993'de yurda dönerek Bilkent Üniversitesi Tarih bölümünü kurdu ve yirmi yılı aşkın bir zaman süresince burada da dersler verdi ve pek çok öğrenci yetiştirdi. Ölümüne kadar bu görevde kaldı, bilime, eğitime ve tarihe adanmı̧̧ ömrünü burada itmam etti. Bilkent Üniversitesi 2003'de Halil Hoca'nın çeşitli arşivlerden topladığı belge ve defterlerin nüshalarını, yarım kalmış araştırma metinlerini ve çeşitli dergi ve kitap koleksiyonu başta olmak üzere, bazı önemli Osmanlı arşiv kaynaklarını da araştırmacıların kullanımına sunduğu Halil İnalıık Center for Ottoman Studies adlı araştırma merkezini kurdu.

Halil Hocamız, 20. yüzyılın sona erdiği yıllarda Cambridge Uluslararası Biyografi Merkezi tarafindan dünyada sosyal bilimler alanında sayılı 2000 bilim insanı arasında gösterildi. 2002'de T. C. Kültür Bakanlığı Kültür ve Sanat Büyük Ödülü'ne lâyık görüldü. Columbia, Princeton, Pennsylvania ve Harvard üniversitelerinde ziyaretçi profesör olarak dersler veren Halil İnalcık, Osmanlı Türkçe'sinin imparatorluğun kuruluşundan sonuna kadar bütün çağlardaki tezahürüne ve kavramsallaştırılmasına katkıda bulundu. İyi düzeyde İngilizce, Fransızca, Almanca ve orta seviyede Arapça, Farsça ve İtalyanca biliyordu. Çalışma alanları arasında Osmanlı siyasi, sosyal ve ekonomik tarihinin yanı sıra Osmanlı hukuku, toprak rejimi, timar sistemi, şehir tarihi, çözülme ve reform dönemlerinde sosyo-ekonomik değişim ve dönüşümler yer almıştır.

Halil İnalcık'ın hayatında belirlediği en önemli hedefi, Türklerin tarihini yabancı gözüyle değil, Türk gözüyle yazmak oldu ve ömrü boyunca bunu gerçekleştirmeye çalışt1. Ana kaynağ1 arşiv belgeleri oldu. Böylece elindeki verilerin ve arşiv belgelerinin 1şı̆̆ında olguya sadık ve hakkaniyetli bir tarih anlayışı izledi. Osmanlı tarihinin, dünya tarihi içinde saygın bir yer edinmesindeki en önemli katkının İnalcık Hoca'ya ait olduğu yadsınamaz.

Yaklaşık on yıl önce Kurulus Dönemi Osmanlı Sultanları kitabının yayına hazırlanmasında ona yardımcı oluyordum. Bir araya geldiğimiz, telefonda 
konuştuğumuz, bazen de Ankara'ya gittiğimde mutlaka kendisini ziyaret ettiğim anlar oluyordu. Uzunca bir aradan sonra kendisini ziyaret etme firsat1 bulduğum bir defasında kendisine sormuştum: "Hocam nasılsınız?” Bu sıradan soruya hiç unutamayacağım şu nükte dolu cevabı vermişti: "Seyficiğim, iyiyim, yürüyebiliyorum ve çalışmalarıma devam edebiliyorum. Galiba Yüce Allah Osmanlılar'ı sevmişti, çünkü onlara uzun bir ömür verdi, zira yeryüzünde [aynı hanedan idaresi altında] en uzun yaşayabilen imparatorluk onlara nasip olmuştu. Ben de Osmanlılar'ı çalışıyorum, araştırıyorum, bu sebeple galiba beni de seviyor ve böylece bana da uzun bir ömür veriyor." Bu cevabında galiba haklıydı. Bir asırlık ömürden sonra sevdiği ve hakkaniyetle özel bir emek verdiği Fatih'in dünyasında yerini aldı; haziresine defnedildi.

Bizler de kendisini rahmet ve minnetle yâd ediyoruz ve bizler de -Hoca'ya imtisalen- kendimiz için Yüce Yaratıcı'dan, merhum hocanın bütün eserlerini okuyabilecek ve arkada bıraktığı evrakını değerlendirebilecek, yarım kalan projelerini itmam edebilecek kadar uzun bir ömür diliyoruz. Kimbilir, dilemenin makbuliyetindeki sır belki de hocanın isminde gizlidir!

Halil Hocamızın bütün eserlerini burada tek tek tadâd etsek küçük bir kitapçık olur. Bu nedenle sadece başlıca eserlerine yer vermekle yetineceğiz:

- Tanzimat ve Bulgar Meselesi, Ankara: TTK, 1943.

- Hicri 835 Taribli Suret-i Defter-i Sancak-ı Arvanid, Ankara: TTK, 1954.

- Fatih Devri Üzerinde Tetkikler ve Vesikalar, Ankara: TTK, 1954.

- Kanûnnâme-i Sultânî ber Mûceb-i Örf-i Osmanî: II. Mehmed ve II. Bayezid Devirlerine Ait Yasaknâme ve Kanûnnâmeler, Ankara: TTK, 1956 (R. Anhegger ile birlikte).

- The Ottoman Empire: the Classical Age, 1300-1600, London: Weidenfeld and Nicholson, 1973.

- Gazavât-ı Sultân Murâd b. Mehemmed Hân İzladi ve Varna Savaşları (1443-1444) Üzerinde Anonim Gazavâtnâme, Ankara: TTK, 1978 (M. Oğuz ile birlikte).

- Tursun Beg, The History of Mehmed the Conqueror, Chicago-Minnesota: American Research Institute, 1978 (R. Murphey ile birlikte).

- The Ottoman Empire: Conquest, Organization and Economy, London: Variorum Reprints, 1978. 
- Türkiye'nin Sosyal ve Ekonomik Taribi / Social and Economic History of Turkey (1071-1920), Ankara: Meteksan, 1980 (editör, O. Okyar ile birlikte).

- Studies in Ottoman Social and Economic History, London: Variorum Reprints, 1985.

- Osmanl Imparatorluğu Toplum ve Ekonomi Üzerinde Arşiv Çalş̧maları, İncelemeler, İstanbul: Eren, 1993.

- The Middle East and the Balkans under the Ottoman Empire, Bloomington: Indiana University Turkish Studies and Turkish Ministry of Culture Joint Series Volume 9, 1993.

- The History of the Black Sea Trade: the Register of Customs of Caffa. Cambridge: Cambridge University Press, 1993.

- Süleyman the Second and his Time, İstanbul: Isis Press, 1994 (editör, C. Kafadar ile birlikte).

- An Economic and Social History of the Ottoman Empire, Cambridge: Cambridge University Press, 1994 (1300-1600 arasını Halil İnalcık yazdı, editör, D. Quataert ile birlikte).

- From Empire to Republic: Essays on Ottoman and Turkish Social History, İstanbul: Eren, 1995.

- Essays in Ottoman History, İstanbul: Eren, 1998.

- Osmanl, İstanbul: Yeni Türkiye Yayınları, 1999 (editör, N. Göyünç, E. İhsanoğlu, Y. Halaçoğlu ile birlikte), 12 Cilt.

- Osmanli'da Devlet, Hukuk, Adâlet, İstanbul: Eren, 2000.

- Şâir ve Patron, Patrimonyal Devlet ve Sanat Üzerinde Bir İnceleme, Ankara: Doğu Batı Yayınları, 2003.

- Osmanlı Uygarlğg//Ottoman Civilization, İstanbul: Kültür Bakanlığı, 2004 (editör, Günsel Renda ile birlikte), 2 Cilt.

- Doğu Batı Makaleler I, Ankara: Doğu Batı Yayınları, 2005.

- Tanzimat / Değģisim Sürecinde Osmanl İmparatorluğu, Ankara: Phoenix Yayınları, 2006 (editör, M. Seyitdanlığlu ile birlikte).

- Turkey and Europe in History, İstanbul: Eren, 2006.

- Atatürk ve Demokratik Türkiye, İstanbul: Kırmız1 Yayınları, 2007.

- Kuruluş Dönemi Osmanli Sultanlar, İstanbul: İSAM Yayınları, 2010.

- Osmanl Taribinde İslamiyet ve Devlet, İstanbul: İş Bankası Yayınları, 2016. 